\title{
Materiality, Making and Meaning: Building the Artist Record through Conservation in Indonesia
}

\author{
Eliza O'Donnell, PhD Candidate, \\ Grimwade Centre for Cultural Material Conservation, University of Melbourne \\ elizao@student.unimelb.edu.au
}

Dr Nicole Tse,

Grimwade Centre for Cultural Material Conservation, University of Melbourne

nicoleat@unimelb.edu.au

\begin{abstract}
Ways of knowing and understanding the artistic process are not fixed, and there are multiple perceptions that rely on the experience of the viewer and sources that inform them. This paper presents a case study of a conservation residency and collaborative treatment of Indonesian artist Entang Wiharso's ‘Landscaping My Brain' (2001) oil on canvas triptych painting, to examine how we understand the artistic process from a conservation perspective and how this material knowledge contributes to the artist record. An interdisciplinary methodology for the conservation treatment of Wiharso's painting relied on technical and visual examination of the artwork in partnership with artist interviews and archival research. The residency concluded with an exhibition of the painting in an 'active state of conservation', highlighting the conservation decisionmaking process as value based and culturally grounded, leading to questions of authority, the role of technical-conservation expertise, what approaches work best, who should do the work and what knowledge informs it. In considering how we understand the artistic process, this paper will draw on the importance of practice-based interdisciplinary learning between conservator, artist, collector, curator and students, and the potential for collaboration and knowledge building at the intersection of these disciplines.
\end{abstract}

Keywords: conservation, knowledge sharing, painting, interdisciplinary

\section{INTRODUCTION}

When considering an archive, we often ask, "Who built this archive and for what purpose?" (Melani Setiawan 2018)

These questions are at the root of understanding why Dr Melani Setiawan began documenting her interactions with the art world in Indonesia and how this personal project has evolved into the largest single collection of photographs of the Indonesian art world in the last 40 years (Setiawan, personal communication, May 2018). The cultural and historical significance of Melani's art collection and personal archive lie in the personal relationships she establishes with the artists themselves. Known as the 'Mother of Indonesian Fine Art' and considered to be one of the most influential figures in the contemporary Indonesian art world today, Melani does not identify as a collector in the traditional sense, rather as an art lover, close friend and support network to many artists and individuals 
in the Indonesian art community (Setiawan, personal communication, May 2018). The diversity of Melani's collection, which includes approximately 600 paintings, sculptures, drawings and new media works, is a reflection of and testament to the strong relationships she has built with Indonesian artists and cultural practitioners across time, practice, region and community. In 2012, Melani's personal archive of 45,000 photographs documenting art world events over the past three decades was recognised by the Indonesian Museum of Records (Museum Rekor-Dunia Indonesia \{MURI\}) for its excellence in 'Photo Documentation of the Most Fine Art Activity Interactions' (MURI 2018), this award coinciding with the RE-CLAIM exhibition at Galeri Nasional Indonesia (the Indonesian National Gallery) which presented new work from 60 Indonesian contemporary artists inspired by Melani's personal archive (Cocca 2012). More recently, in 2017 the exhibition Saya Datang (Here I Come) at Taman Budaya Yogyakarta, presented 70 paintings and sculptures from Melani's collection prior to 2007. Alongside the artworks, the exhibition featured testimonials and photographs from Melani's archive, presenting the archive as an active site of cultural production and highlighting the history of her relationships with the artists and the Indonesian art world (Suhari, 2018).

Melani's collection of photographs takes viewers inside the homes, studio gatherings, exhibitions and discussions to witness the Indonesian art worlds shifting landscape, the flux of three decades of presentation, negotiation collaboration and confrontation amongst the members of the Indonesian art community (Cocca 2012). This personal archive, art collection and historical record of Indonesian art world events inform and contribute to a record of contemporary Indonesian cultural production since 1977. The verification of histories and development of identity require the existence of, and access to, an authentic cultural record - a tool for understanding the past, to make decisions for the future (Sloggett 2018). The inaugural Australia Indonesia Art Forum (AIAF) conservation residency was conceived within the context of Melani's culturally significant collection and a recognised need to preserve and care for a selection of paintings at Rumah Melani (Melani House), Yogyakarta. Working with the painting collection, the conservation residency was established in response to the tropical climate preservation challenges associated with cultural collections in Indonesia, limitations in conservation training, recognised expertise in the region and the opportunity to undertake a conservation project grounded in knowledge sharing. Based at RuangDalam art house in Yogyakarta, the three month residency involved the treatment of an oil on canvas triptych 'Landscaping my Brain' (2001) by Entang Wiharso, followed by an exhibition of the painting highlighting the conservation process exhibited at the conclusion of the residency. Drawing on the treatment of Wiharso's painting as a case study, this paper is presented from the perspective of a conservator working in collaboration with Melani Setiawan, Entang Wiharso and the residency team of art students, curators, writers and cultural practitioners from RuangDalam art house. Exploring the potential for collaboration and knowledge building at the intersection of these disciplines, 
this research aims to critically question and expand disciplinary frameworks for cultural material conservation knowledge sharing as a methodology for building artist records in Indonesia and aims to contribute to the cultural record of Melani's archive and collection.

\section{METHODOLOGY: BUILDING AN ARTIST RECORD}

The conservation of objects, collections, archives and sites is a practical and philosophical response to both material changes over time and the cultural dynamics related to these objects (Eastop 2006). As such, conservation as a practice evolves over time and place and is shaped by inter-regional dialogue (Tay 2015); regionally relevant preservation solutions; access to conservation grade materials and culturally embedded ways of knowing. However, ways of knowing and understanding the artistic process are not fixed, and there are multiple perceptions that rely on the phenomenological experience of the viewer and sources that inform them (Eastop 2006; Tse et al 2018). This research draws on an interdisciplinary methodology for building material knowledge to inform the treatment process and the artist record. Visual and technical examination of the painting from a conservation perspective, is complimented by information drawn from interviews with artist, Entang Wiharso, focussing on the production of the painting, and custodian, Dr Melani Setiawan, providing information on the artworks history and provenance. Visual examination, artist expertise and questions of practice and production are located within the framework of the residency program, which provided a space for contextualised artistic practices to be put into conversation with broader questions of engagement and knowledge embedded in the community.

Figure 1. outlines the research methodology utilising a multidisciplinary approach based on conservation, artist, custodian and community knowledge and expertise. The central hypothesis being that these avenues of enquiry are interdisciplinary in their scope and rely on multiple perspectives to build a robust body of material knowledge and documentation to inform further research and questions of authorship, centres of conservation expertise and authenticity as they arise. The diagram presents an intersection of historical, archival and technical pathways that inform our knowledge of artistic production, and how these areas of enquiry relate to each other. The residency framework is presented as a modality for 'beyond-text' research methods to deliver co-produced research with the wider art community (Beebaujaun 2013). This approach is based on the demonstrated benefits of decentralising Western informed conservation knowledge pathways and finding new ways of serving society and gaining material knowledge by working directly with artists, collectors and communities (Scott 2015, p. 4, Williams 2013). As cultural material conservation practices continue to emerge in Indonesia, this development is based on principles of intercultural and intergenerational enquiry and requires conservation practices to be fully engaged with wider society and its many diverse cultures and value systems (Scott 2015, p. 3). This methodology aims to examine how a material investigation grounded 
in interdisciplinary conservation enquiry can contribute to the cultural record and asks, what material knowledge do we need to create an authentic cultural record? Where does this knowledge live and who or what informs it?

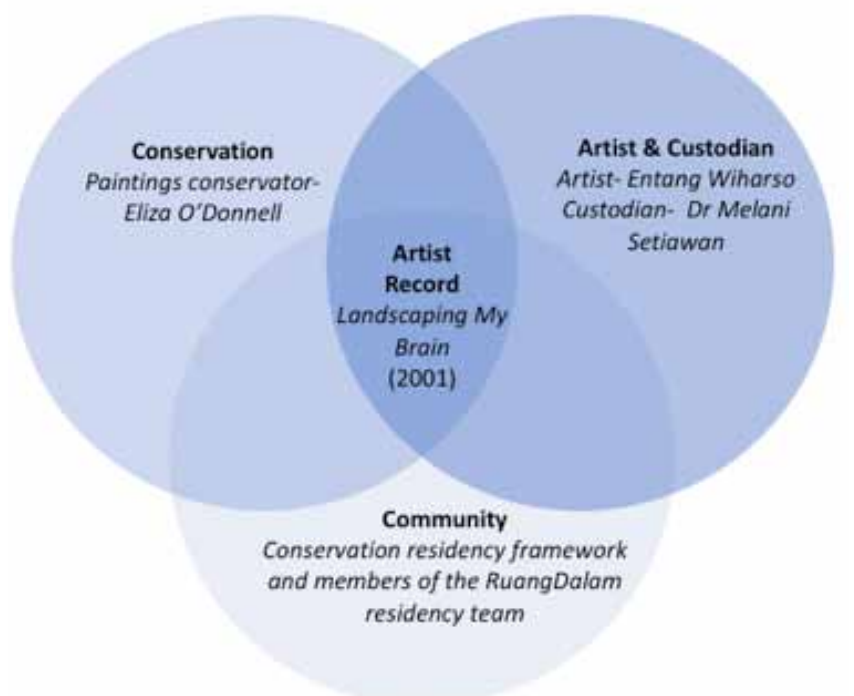

Figure 1. Interdisciplinary methodology for building the artist record based on conservation, artist and custodian and community expertise.

\section{CONSERVATION PRACTICE IN INDONESIA: AN EMERGING DISCIPLINE (?)}

Traditional and contemporary works of art in Indonesia, and the wider Asia Pacific region, are important in the development of national identity and collective cultural memory, yet research on their conservation and preservation has not been a major focus of research in our region until recently (APTCCARN 2018). As the conservation and research of cultural material in tropical climates is an area that has begun to receive more attention in recent years, questions asked in cultural heritage studies "have graduated from 'how to conserve?' to 'why conserve?' and they are now grounded in questions of 'for whom to conserve?' (Luxen (2004) cited in Esposito 2014). Esposito argues that this reflexive approach has gained momentum in the social sciences during recent years, where acknowledgement of these knowledge gaps and asymmetries have resulted in networks dedicated to addressing tropical climate preservation issues (Esposito 2014). Research conducted by the Association of Critical Heritage Studies (ACHS), the Southeast Asian Regional Centre for Archaeology and Fine Arts (SEAMO SPAFA) and the Asia Pacific Tropical Climate Art Conservation Research Network (APTCCARN) are working towards addressing knowledge gaps associated with conservation and critical heritage studies in the Asia Pacific region. With a goal to support Asia focused cultural materials conservation research and practice, APTCCARN meetings provide an opportunity for face-to-face exchange and have been held in Malaysia (2008), Melbourne (2009), Thailand (2012), Taiwan (2015) and the Philippines (2017). The respective themes of the meetings mirror the tension between a material-based approach to a dialogic and socially 
situated examination of cultural materials conservation in the Asia Pacific region (Tse 2018). Other events and workshops highlighting conservation activity in Indonesia include 'Training in Painting Conservation: Prevention, Restoration and Maintenance' workshop at Yayasan Arsari Djojohadikusumo (YAD) in Jakarta, 2015; 'Conversation on Conservation' public seminar at Bentara Budaya Jakarta in May, 2018 and the 'International Seminar on Cultural Management, Conservation, Research and Innovation' at the Bandung Institute of Technology (ITB) in August, 2018.

Building on these events as critical platforms for disseminating conservation knowledge and the scope of Asia focused research networks in promoting conservation through practical and observational engagement, the residency was built within a framework for inter-personal exchange, relationship-building and action-based conservation research based on a prolonged and collaborative approach to knowledge making and production.

\section{CONSERVATION RESIDENCY/RESIDENSI KONSERVASI}

Each year a number of art houses and independent organisations in Yogyakarta facilitate residency programmes which provide an opportunity for artists from abroad to interact and engage with artistic production in a local context. A traditional residency format provides the artist with time and space away from their local working environments, these new surroundings creating opportunities for networking or cross-cultural exchange to create new body of work (Bahdam, Hill, Purves, Cockrell and Spiers, 2016). Building on this model, the AIAF conservation residency was invited to take place at RuangDalam art house in Yogyakarta, the art house providing a studio, gallery, residence and meeting place for the treatment and exhibition to occur over the three month residency period from March-May 2018. As an Australian paintings conservator and researcher new to Indonesian studies, the art house provided a supportive environment to undertake the project in collaboration with a team of local professionals familiar with the artworks in Melani's collection. The residency team included art students from Institut Seni Indonesia (Indonesia Institute of the Arts [ISI]), curators, photographers, graphic designers, writers, artists and cultural material practitioners based in Yogyakarta, each individual drawing on their expertise to contribute to the collection assessment, documentation, treatment, workshop and exhibition preparation and install.

The first week of the residency was dedicated to establishing the conservation studio, sourcing materials and assessing a number of paintings at Rumah Melani that had been flagged for conservation intervention. The team of ISI art students managing the collection at Rumah Melani participated in the visual assessment of approximately 20 artworks, ranging from mid-twentieth century oil paintings to contemporary acrylic and mixed media artworks. Sharing knowledge on the collection and creating a space for mutual exchange of ideas about the artworks and their history was essential to the success of the collaborative project. During this time, an understanding of deterioration mechanisms and level of damage was 
established, which informed what conservation materials would be required to begin the treatment process.

As such, in addition to a small selection of conservation materials brought from Australia, locally available proprietary products were purchased for use in the studio during treatment. A small handheld vacuum and artist quality brushes for brush vacuuming the back of paintings; bamboo skewers and sheets of cotton for rolling swabs and a small handheld ultraviolet (UV) torch, traditionally used in retail outlets for verifying the authenticity of bank notes, which can be used in conservation to determine the presence of a varnish layer. However, the availability of specific conservation grade materials presented limitations to what treatments could be undertaken, with specific reference to chemical solvents used for cleaning painted surfaces, adhesives for consolidation of flaking paint layers and relining materials for repairing structural damage to torn canvases. As conservation practices in Indonesia are evolving and continue to develop, many local conservation laboratories and private practitioners source these materials from overseas, and restrictions to what can be brought on a plane or imported at short notice meant that some treatments requiring these materials could not be performed. This alone raises questions about the suitability of imported materials and the limited incorporation of local knowledges on the behaviour and performance of Indonesian sourced materials. It points to a universal, practiced based discourse of materials conservation that relies on standards of chemical durability and performance and Luxen's 'how to conserve' (2004). In ontological terms, the tools and actions of materials conservation are still very much characterised by expert knowledges. This was very much recognised during the residency and was a point of navigation.

During the assessment period, one painting was identified as requiring urgent conservation treatment due to the extensive paint loss and the cardboard that had adhered to the painted surface. Based on the availability of the conservation materials required to begin the treatment and the significance of the painting to Melani's collection, a large scale oil on canvas triptych painted in 2001 by Entang Wiharso, $(600 \mathrm{~cm} \times 97 \mathrm{~cm})$ was selected as the focus of the conservation residency treatment project (Figure 2).

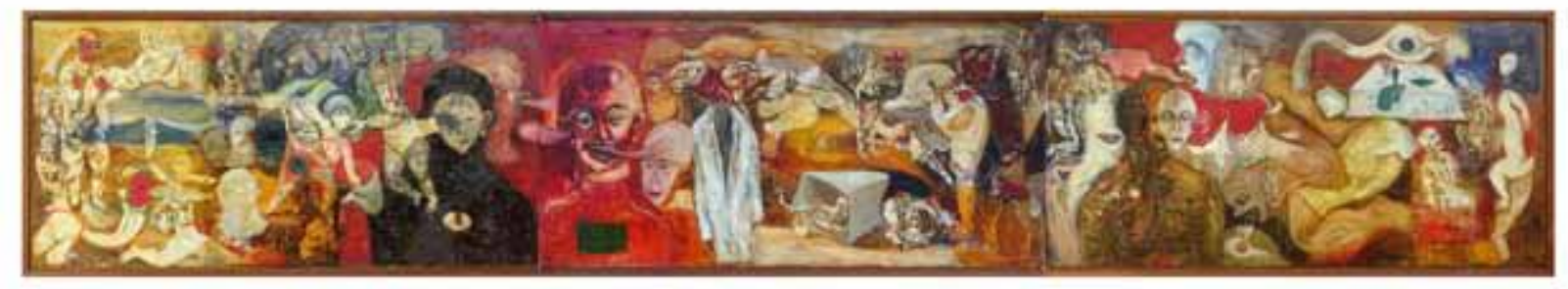

Figure 2. Before treatment: 'Landscaping My Brain' by Entang Wiharso (2001), oil on canvas triptych. Panel one, two and three (from left to right). Photograph by Harry Arafat, March 2018 


\section{VISUAL ASSESSMENT OF 'LANDSCAPING MY BRAIN’}

The conservation of paintings usually takes into account properties such as its structure, material and chemical composition and visual appearance, as well as its 'living' relationships such as its cultural and social values that it embodies and historical information which locates its provenance and measures of esteem. In order to build a comprehensive understanding of the artwork, a visual assessment of the painting is compiled into a condition report with written observations and photographic data. In the case of 'Landscaping My Brain', it is made up of three oil on canvas panels that are connected by interlocking horizontal frame members and presented as one whole painting. Each of the three canvases measures $97 \mathrm{~cm}$ $x 200 \mathrm{~cm}(600 \mathrm{~m}$ total in length) and is supported by a stretcher with two vertical cross brace members. Due to the size of the work and the studio space, it was not feasible to work on the painting as a whole, rather each canvas was conserved individually, referred to in the documentation as panel 'Satu' (One), 'Dua' (Two) and 'Tiga' (Three).

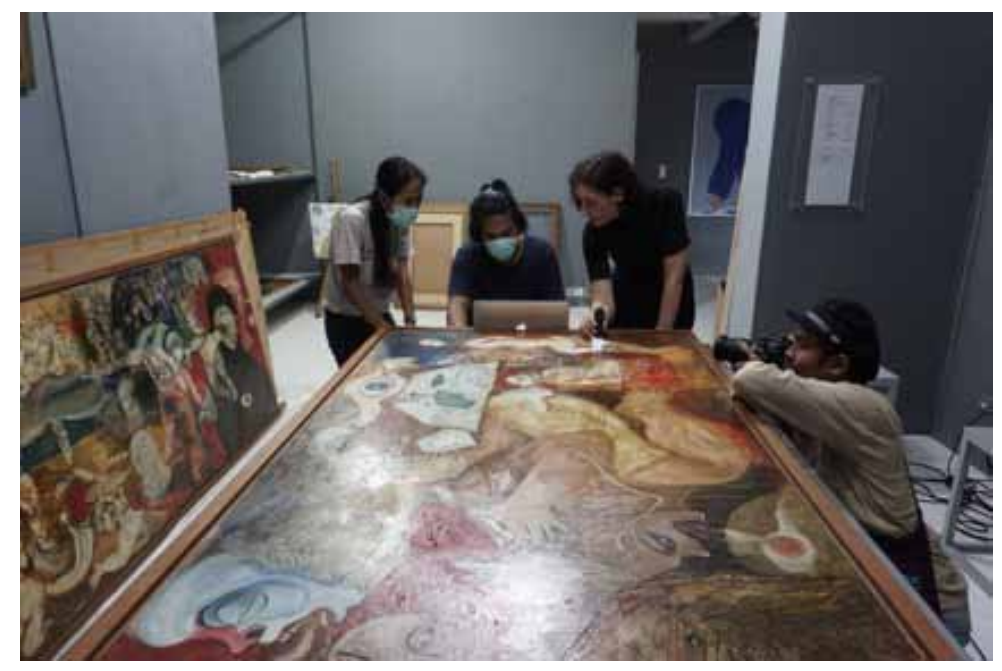

Figure 3. Nova Dwi Jayanti, Andrea Gani Hidayat and Eliza O'Donnell performing digital microscopy to examine the painting surface on a microscopic level. Photograph by Harry Arafat, April 2018

During the visual assessment, three primary mechanisms of deterioration were observed within the paint layer and categorised as mould; accretion; and three levels of media loss classified as minimal, moderate and significant. A summary of each is provided below with images and a description of any early treatment steps that were undertaken to stabilise the artwork.

\section{Mould}

Paintings in tropical climates are highly susceptible to biological deterioration, particularly mould growth. It responds to environmental factors of high relative humidity in excess of $60 \%-70 \%$, high temperatures and collections stored in dark and damp environments with minimal ventilation. Mould spores can grow on any organic surface and commonly feed on the binding medium or the size layer in painting canvas supports. 
In Landscaping My Brain, white mould spores were observed on the body of the dark figure in panel one, suggesting a selective material susceptibility and were successfully removed during the stabilisation process.
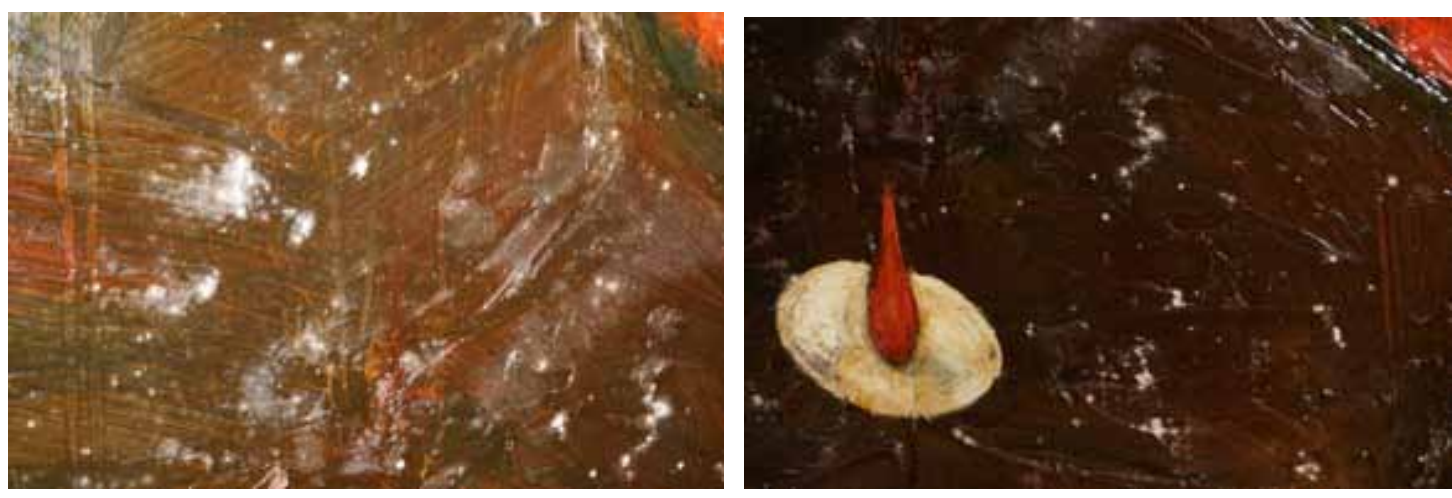

Figure 4 \& 5. White mould observed on panel 'Satu' during visual examination. Photograph by Harry Arafat, March 2018.

\section{Accretions}

An accretion is used to described the accidental addition of non-original 'foreign' material that was not intended as part of the painting process. The cardboard observed in localised areas throughout the three panels can be categorised as an accretion that has adhered to the paint and varnish layer while the artwork was in storage. Proceeding with removing the cardboard from the surface raises questions of original material and artists intent, and consultation with Melani and examination of early photographic evidence of the painting confirmed that the cardboard was not original and should be removed. Throughout the stabilisation process, the cardboard was successfully removed from the surface using a swab with deionised water.
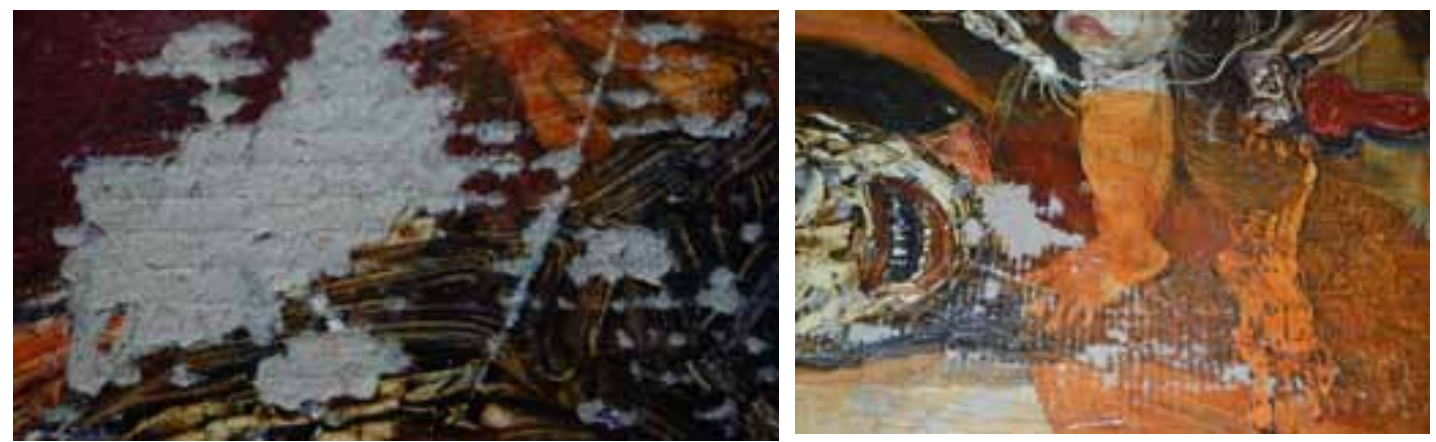

Figure $6 \&$ 7. Cardboard adhered to the surface of panel 'Dua'. Photograph by Harry Arafat, March 2018.

Loss: Minimal, Moderate \& Significant

A 'loss' describes the absence of original material observed in one or more layers of the painting, most frequently occurring as a result of flaking, abrasion, tearing or physical damage. In Landscaping My Brain the areas of 
loss have been categorised as minimal, moderate and significant, each category referring to varying degrees of damage or deterioration resulting in the loss of original material from the artwork. Culturally embedded decisions regarding the introduction of non-original material through a process of aesthetic retouching and who should be authorised in making such decisions was a point of discussion.

\section{Minimal loss}

Areas of minimal loss refer to shallow localised areas observed throughout the composition, where the original upper paint layer has been removed from the painting, exposing the ground or paint layers below. A process of retouching the shallow losses using watercolour, a reversible painting material, was selected to tone back the areas of paint loss and minimise the localised signs of damage and abrasion. The process of minimal retouching aims to restore visual cohesion to the composition where the losses break up the subject matter and distract the viewer from reading the composition. In this case, how is visual cohesion measured, who is authorised to make such judgements and how are such processes culturally and geographically embedded?
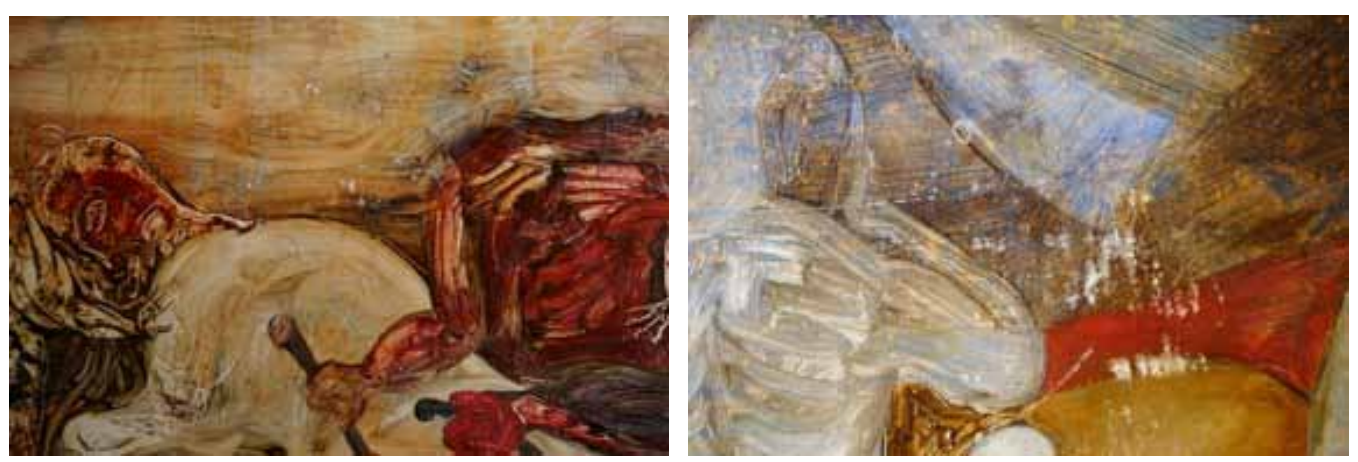

Figure $8 \& 9$. Minimal loss of primary media observed on panel 'Dua' and 'Tiga'. Photograph by Harry Arafat, March 2018.

\section{Moderate loss}

The areas classified as moderate loss refer to the deeper losses that expose the ground layer and require the introduction of an infilling material prior to retouching. These areas are located in background 'non-prominent' areas and some of the moderate losses were filled and toned during this treatment using reversible conservation grade materials. The principle of retreat ability in the selection of retouching materials is usually a key to conservation ethical considerations and allows for any non-original material introduced to the painting to be removed at a later stage. The question is whether the conservation materials with re-treatable characteristics, are the same in the hot, humid climates of Indonesia. 

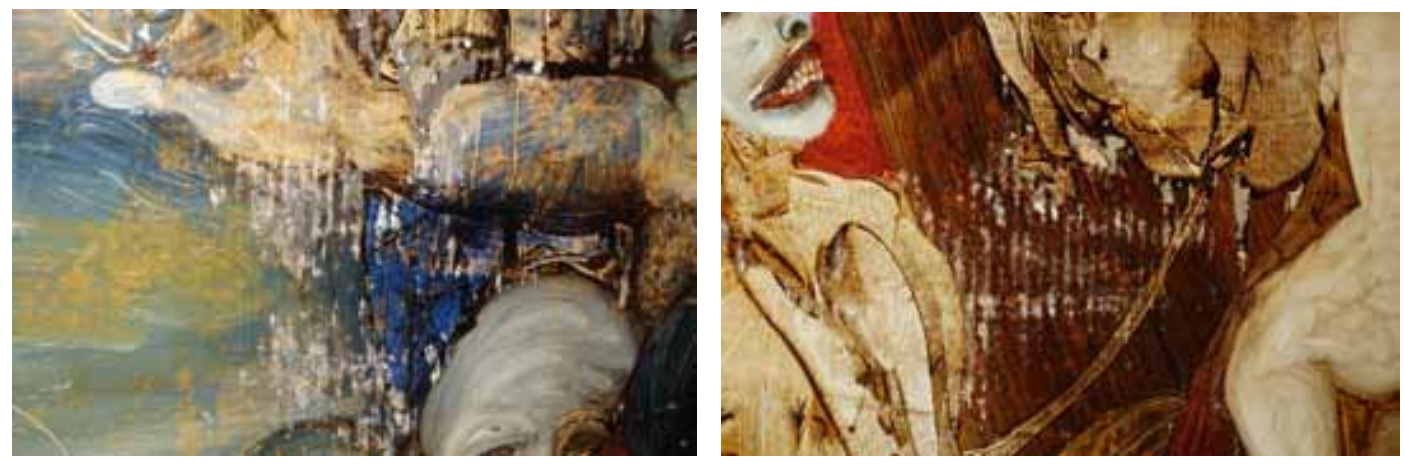

Figure $10 \& 11$. Moderate loss of primary media observed on panel 'Satu' and 'Tiga'. Photograph by Harry Arafat, March 2018.

Significant loss

Areas of loss that were categorised as significant demonstrate widespread deterioration of the original paint layer through extensive media loss and are located in prominent areas within the subject matter, such as the face of the figures in each of the three panels. In consultation with Wiharso, the decision to leave the areas of significant loss untreated at this stage was made based on limited time, conservation grade resources and ethical considerations regarding interventive treatment steps and the role of the conservator. This approach further highlights the conservation decision making process and the need for collaboration and communication with relevant stakeholders will be examined in further detail shortly.

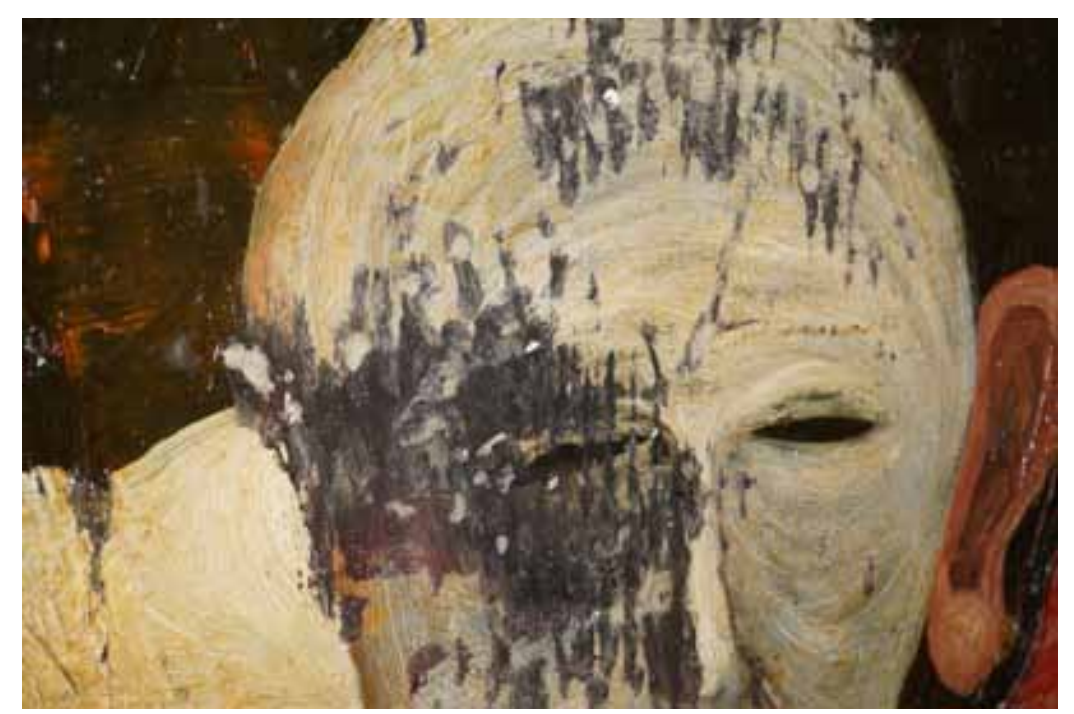

Figure 12. Significant loss of primary media observed on the face of the central figure in panel 'Satu'. Photograph by Harry Arafat, March 2018.

During the visual condition assessment, it was evident that the three panels each exhibited similar signs of damage, most notable was the presence of thick cardboard adhered to the surface of the paint layer in localised areas. Based on the thick paint and varnish layer, it is likely that while the paintings were in storage, the media layers softened in high temperatures, and the cardboard adhered to the 
surface while the paint was in a soft and malleable state. Further to the cardboard, there were areas of loss of original media, inconsistent levels of yellowing varnish layer and localised areas of mould growth, predominately located on the dark figure of panel one. Mould growth was observed on each panel presenting a significant risk to collections in Yogyakarta and the need for regionally relevant approaches. Discussion with Setiawan and Wiharso, was required to determine further information about the paintings, materials and how they view its trajectory-which would inform the treatment going forward.

\section{ENTANG WIHARSO'S PAINTING PRACTICE}

Wiharso painted 'Landscaping My Brain' in less than two weeks in November of 2001, working in the evenings at Melani's residence in Jakarta where he was staying throughout the duration of his NusaAmuk exhibition at Galeri Nasional Indonesia (National Gallery of Indonesia) (Wiharso, personal communication, April 2018).). In an interview with Wiharso in April 2018 at his studio in Yogyakarta, the artist described his use of materials as a process of experimentation; mixing oils, animal glues and pigments in his large scale canvas paintings (Ibid). Focusing on the idea as the starting point, Wiharso usually begins with a conceptual approach to his artworks, using composition, colour and form to explore his ideas on the canvas, followed by a process of improvisation with the materials (Ibid). Using rabbit skin glue as a priming layer, Wiharso undertook the canvas preparation for 'Landscaping my Brain' himself, rather than purchasing a prepared artist canvas, priming the linen support with a rabbit skin glue size layer and building the ground up in a three layered structure (Ibid). Rabbit skin glue is a traditional canvas size layer which protects the raw canvas fibres from the disintegrating effects of fatty acids in oil based colours and grounds. Following the size layer, Wiharso applied a 'triple layered ground' to achieve a smooth surface to begin painting. Beginning with a white gesso acrylic ground, followed by a deep dark purple/grey and then an orange layer, this multi-layered ground structure was observed during visual analysis through different areas of loss which highlight the depth of the paint layers and provide an understanding of Wiharso's painting technique. The final step prior to beginning the painting, Wiharso often uses charcoal or oil as a preparatory underdrawing to map out the composition.

Wiharso favours Winsor and Newton or Rembrandt as his preferred oil paint brands, and Golden when working with acrylics. Since 1997, Wiharso has divided his time between Yogyakarta, Indonesia and Rhode Island, USA, and prefers to purchase paints when he is in America as there is a larger variety of materials available and they are more affordable (Ibid). In 'Landscaping My Brain' Wiharso has used a combination of painting techniques working with brushes and palette knifes to create lines and textures in the surface, achieving varying levels of transparency and opacity in the paint layer. Figure 13 from Melani's archive shows Wiharso during the painting process in 2001, working on panel Satu, with Dua positioned by its side. In Figure 13. The composition of Satu appears almost 
complete and the image shows a collection of skewers in a bucket of water next to Wiharso as he is working in front of the canvas. It is likely that Wiharso used the skewers to carve out lines in the painted surface creating texture and exposing the layered ground underneath.

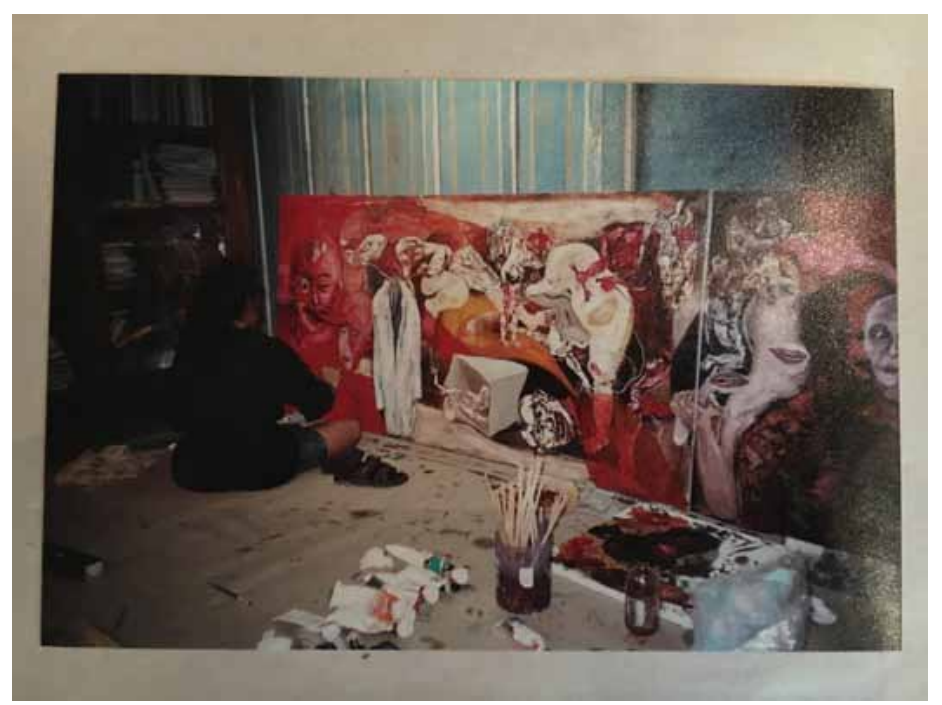

Figure 13. Entang Wiharso painting 'Landscaping My Brain' at Melani's residency in Jakarta, 2001, from Melani Setiawan's personal archive.

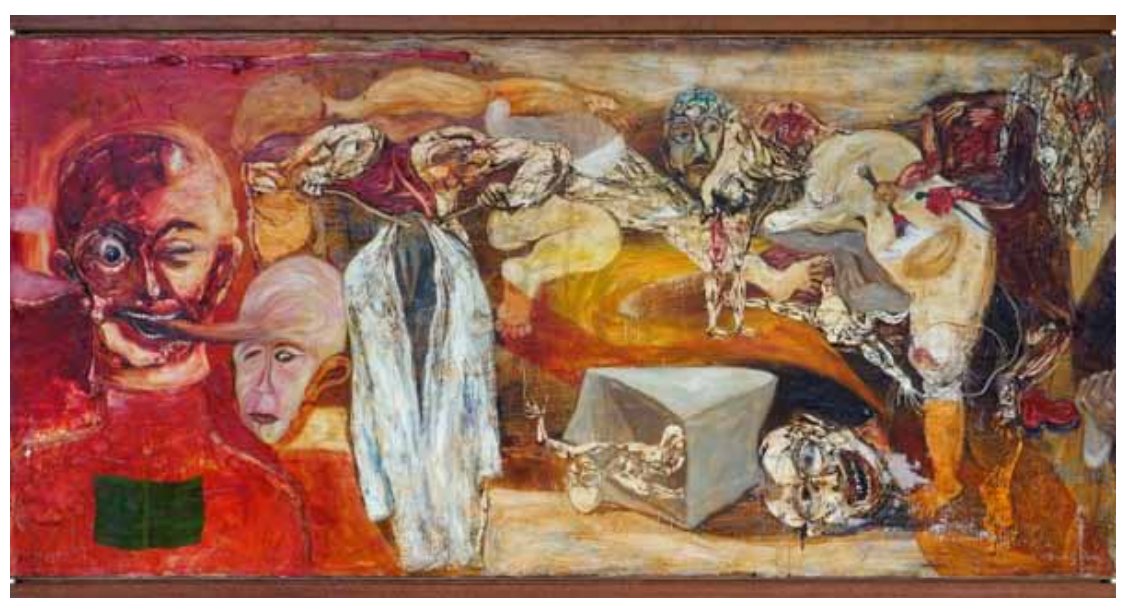

Figure 14. Panel ‘Dua' from Entang Wiharso's 'Landscaping My Brain' (2001). Photograph by Harry Arafat, March 2018.

The basic premise that guides the current work is that the physical landscape always has a connection to, or reflects, the interior landscape of a community.

(Wiharso 2003)

Liaising with Melani throughout the residency provided an opportunity for consultation regarding the treatment decision making process as she provided crucial information on the history and biography of the painting and its significance to her collection. Executed at her home in Jakarta, Wiharso's painting hung on the mezzanine floor wall overlooking Melani's living room for a number of years, prior to its storage and subsequent transit to Rumah Melani in Yogyakarta (Setiawan, personal communication, May 2018). The surreal and abstracted 
dreamlike world of 'Landscaping My Brain' is embedded with motifs and symbolism that is consistent with Wiharso's oeuvre, with particular reference to the paintings shown in the NusaAmuk exhibition at Galeri Nasional Indoneisa from May $15^{\text {th }}-30^{\text {th }} 2001$. An overt reference to Melani's professional medical practice is represented by the white medical coat in panel 'Satu' (Figure 14), as well as several anatomical limbs observed throughout the composition. This is a painting created specifically by Wiharso for Melani, and when asked about the symbolism and hidden meanings in our interview, Wiharso did not elaborate and alluded to the personal dialogue that exists between artist and friend (Wiharso personal communication, April 2018).

During a visit to the archive in Jakarta, Melani produced a certificate of authenticity signed by Wiharso along with individual photographs of each panel on the back. This archival evidence provides a verifiable link and secure provenance connecting the production of the painting to the artist's hand which is tied directly to Melani's collection. Furthermore, the photographs taken in 2001 confirm the original appearance of the primary media showing the varnish layer has significantly yellowed over time and the original colours were cooler and brighter. This valuable primary documentary source data builds our understanding of the historical trajectory of the painting from its inception in Jakarta in Melani's home, to its current location in Rumah Melani in Yogyakarta.

Each year in May, the Yogyakarta art world welcomes the opening of Artjog, an annual interdisciplinary exhibition of visual arts, music, dance and performing arts held at the Jogja National Museum. During this time, a number of art houses and galleries in Yogyakarta host parallel events and exhibitions highlighting the immense artistic output of South Java's 'cultural hub'. On the $3^{\text {rd }}$ of May 2018 the Landscaping My Brain (2001), Artwork by Entang Wiharso, Painting Conservation project by Eliza O'Donnell exhibition opened at RuangDalam art house, showcasing the residency activities and the treatment undertaken on Wiharso's painting over the last three months. The painting was presented in an 'active state of conservation', raising discussions around perceptions of damage, to what level artworks should be conserved, and around time, resources and the unique conservation treatment requirements for Indonesian collections. Viewing the painting from the perspective of the conservator, the exhibition focused on the materials and techniques, mechanisms of deterioration, archival documentation and information gained directly from the artist and custodian, demonstrating how these avenues of enquiry are used to inform a holistic understanding of the artwork to develop an appropriate treatment methodology.

The exhibition was used as a platform to demonstrate the scope of the residency as a truly collaborative project made possible by many members of the RuangDalam residency team. Co-productive and collaborative research is a response to these challenges which offers a way of recognising the resource contribution of communities to research and emphasizing the conduct of researching 'with' communities rather than 'on' communities (Beebeejaun 2013). 
Furthermore, the exhibition demonstrates how conservation can enhance viewer's interactions with works of art, illuminating the skills that are brought into practice in the creation of the work and contributing to a broader access to this material knowledge in present and future.

\section{CONCLUSION}

It is not often that conservators are given the opportunity to share their decision making process in a public forum, and it is even more rare that a painting in the process of a treatment is presented in an exhibition to highlight this decisionmaking framework. However, in advocating for interdisciplinary research and conservation practices in Indonesia, this transparency and active engagement with the treatment is an important step in developing an awareness of preservation issues within tropical climate collections. Drawing on the case study of Entang Wiharso's painting within Melani Setiawan's collection, this research aims to highlight the importance of working across disciplines to build the artist record, working with artists, custodians and community members to build a robust body of material knowledge. Approaching cultural materials conservation in Indonesia as a field of multi-directional connections, requires local assemblages of heritage notions, measures and practices, coming from various backgrounds, and re-contextualised in the strategic agendas of the stakeholders involved in conservation (Esposito 2014). Building on conservation practice as a starting point to build the artist record relies on this interdisciplinary process of knowledge sharing and exchange.

\section{REFERENCES}

Asia Pacific Tropical Climate Conservation Art Research Network (APTCCARN). 2018. Our History. Retrieved from: https://www.aptccarn.com/about-us/

Badham, M, Hill, K, Purves, T, Cockrell, S and Spiers, A. 2016. 'Forms for Encounter and Exchange: Field School as Social Form at Laughing Waters Artist Residency' in Unlikely, Issue 02. Retrieved from: https://unlikely.net.au/issue-2/forms-forencounter-and-exchange

Beebaujaun, Y. 2013. 'Beyond Text': exploring ethos and method in co-producing research with communities'. Community Development Journal, Oxford University Press.

Cocca, C. 2012. - to be confirmed.

Eastop, D. 2006. Conservation as Material Culture in Tilley, C, Keane, W, Kuchler, S and Spyer, P (Eds) Handbook of Material Culture, (pp. 516-533). London, England: Sage Publications.

Esposito, A. 2014. 'Theorizing heritage in Asia as an 'encounter". The Focus. 69. 19 21.

Luxen, JL. 2004. 'Reflections on the Use of World Heritage Charters and Conventions'. Getty Conservation, Institute Newsletter, 19(2), pp. 4-9.

Museum Rekor-Dunia Indonesia (MURI). 2018. Retrived from webpage: http://muri. org/?s=melani+setiawan

Scott, M. 2015. Normal and Extraordinary Conservation Knowledge: Towards a Postnormal Theory of Cultural Materials Conservatin. AICCM Bulletin, Vol 36(1), pp. 3-12. 
Suhari, SHM. 2018, January 3rd. For Melani Setiwan, fine art and friendship go hand in hand. Jakarta Post, retrieved from: http://www.thejakartapost.com/ life/2018/01/03/for-melani-setiawan-fine-art-and-friendship-go-hand-in-hand. html

Sloggett, R. J. 2018. Truth and Authenticity public lecture, retrieved from https:// events.unimelb.edu.au/events/10923-truth-and-authenticity

Tay, D, Tse, N and Ho, M. 2015. Glocalising Conservation. Furnace, Issue 1, pp. 36-40.

Tse, N, Labrador, A, Scott, M \& Balarbar, R. 2018. 'Preventive Conservation: People, Objects, Place and Time in the Philippines'. Studies in Conservation, Supplementary Issue - Turin Preprints, vol. 63, DOI 10.1080/00393630.2018.1476963. (accepted 11 January 2018).

Tse 2018 'APTCCARN: Working towards a network of shared material conservation actions', The Newsletter, no. 81 Autumn (accepted 27 August 2018).

Wiharso, E. 2003. Hurting Landscape

Williams. 2013. - to be confirmed

Acknowledgements:

This residency was supported by Konfir Kabo and Monica Lim from the Australia Indonesia Arts Forum and Project 11. Further acknowledgements to the RuangDalam Art House team, Bayu Whardana, Gusmen Heriadi, Titik Suprihatin, Nova Dwi Jayanti, Andrea Gani Hidayat, Harry Arafat and Bayu Adi Pujo Asmoro for their support and to Dr. Melani Setiawan and Entang Wiharso for their involvement with the residency program. 